\title{
Narrativa del parque temático en Estados Unidos
}

\author{
ELISABet Fonts \\ Centre de la Imatge i la Tecnologia Multimèdia, \\ Universitat Politècnica de Catalunya \\ elisabet.fonts@citm.upc.edu \\ https://orcid.org/0000-0002-9412-181X
}

\author{
JAUME DuRAN \\ Profesor, ensayista y realizador \\ duran.jaume@gmail.com \\ https://orcid.org/0000-0001-9772-3595
}

\section{Narrative in Unated States Theme Parks}

\section{RESUMEN}

¿Qué se necesita para que un parque temático tenga éxito en el público? ¿Qué lo hace diferente a un parque de atracciones? ¿Por qué los parques temáticos necesitan las narrativas para poder tener éxito? Estas preguntas se irán desvelando a lo largo del artículo. Para ello, se ha dividido en tres puntos fundamentales para que un parque temático pueda tener éxito. En primer lugar, hablaremos de la importancia que tiene la temática en un parque temático. Para ello, analizaremos el caso de California Adventure Park en Estados Unidos y su fracaso y qué hicieron para solucionarlo. En segundo lugar, se podrá ver la importancia del mundo y los submundos que rodean el parque y sus atracciones y como ellos van haciendo que los visitantes tengan una inmersión inolvidable. Para finalizar, al igual que en cualquier producción cinematográfica, todo esto no será posible si no se crean unos personajes memorables y fuertes.

\section{PALABRAS CLAVE}

Inmersión; Narrativa; Parques temáticos; Tematización; Tecnología.
ABSTRACT

What does it take for a theme park to be successful with the customers? What makes it different from an amusement park? Why do theme parks need narratives in order to be successful? These questions will be revealed throughout the article. For this, it has been divided into three fundamental points for a theme park to be successful. First of all, we will talk about the importance of the theme in a theme park. To do this, we will analyze the case of California Adventure Park in the United States and its failure and what they did to solve it. Second, you can see the importance of the world and the underworlds that surround the park and its rides and how they are making visitors have an unforgettable immersion. Finally, as in any film production, all this will not be possible if strong and memorable characters are not created.

\section{KEYWORDS}

Immersion; Narrative; Theme parks; Theming; Technology. 


\section{Narrativa del parc temàtic als Estats Units}

\section{RESUM}

Què es necessita perquè un parc temàtic tingui èxit en el públic? Què el fa diferent a un parc d'atraccions? Per què els parcs temàtics necessiten les narratives transmèdia per poder tenir èxit? Aquestes preguntes s'aniran desvetllant al llarg de l'article. Per a això, s'ha dividit en tres punts fonamentals perquè un parc temàtic pugui tenir èxit. En primer lloc, parlarem de la importància que té la temàtica en un parc temàtic. Per a això, analitzarem el cas de Califòrnia Adventure Park a Estats Units, el seu fracàs i què van fer per solucionar-ho. En segon lloc, es podrà veure la importància del món i els submóns que envolten el parc i les seves atraccions i com ells van fent que els visitants tinguin una immersió inoblidable. Per finalitzar, a l'igual que en qualsevol producció cinematogràfica, tot això no serà possible si no es creen uns personatges forts i memorables.

\section{PARAULES CLAU}

Immersió; Narrativa; Transmèdia; Parcs temàtics;Temàtica; Tecnologia.

\section{El origen de un parque recae en la temática}

Samuelson y Yegoiants (2001) exponen que una de las características más importantes que debe tener un parque temático es su temática. Esto le aportará fuerza y carácter. Lukas (2013) apunta que los espacios temáticos tienen como fundamento fundamental una narrativa general que guía al visitante. Sin embargo, una buena inmersión provoca que el visitante se sumerja dentro de la temática. Esto mismo ocurre con los parques temáticos, casinos, tiendas, museos, entre otros. Consideran que para llegar a las masas es muy importante que tenga una temática, pero también una inmersión para así poder vender sus productos. Y eso le da un valor añadido al producto. La inmersión es un término que se está utilizando últimamente para poder atraer más a los clientes para consumir un producto que va mucho más allá. Es decir, de una simple experiencia puede dar lugar a algo que juega con los sentidos. Normalmente, lo están usando para captar a los jóvenes que buscan nuevas experiencias. La RAE (2020) lo define como la Acción de introducir o introducirse plenamente alguien en un ambiente determinado.

Por lo tanto, Clavé (2005) dice que: uno de los objetivos principales es que se utilice una temática bien arraigada y consolidada en un parque temático. Como por ejemplo los paisajes: la estética del entorno aportará motivos, y a la vez, se formarán símbolos que aportarán un significado para el huésped. Podemos decir que la temática que se escoja para un parque temático deberá seguir una estética arquitectónica, colores, formas, música, distribución del espacio, paisaje, etc. Chazaud (1998) expone unos pasos fundamentales para que un parque temático tenga éxito con la temática que ha escogido.

1. La temática debe ser consistente, es decir, que deberá tener suficiente fuerza y tener un mundo lo suficientemente amplio como para enganchar al público. Y, para ello, deberá estar bien definida.

2. La temática debe adaptarse a la visita. Por lo tanto, se constituirá por diferentes fases escénicas y dramática.

3. La imagen que proyecte el parque hacia el huésped deberá ser suficientemente potente para asociarse inequívocamente a la temática, que será la que dé la identidad y la imagen del mundo que se ha creado.

4. La temática se fusionará con todo el entorno, ya sean las tiendas, marketing, la animación, espacio o empleados.

Como observamos en la clasificación de Chazaud (1998), la temática marca la fuerza del parque. Por otra parte, las escenas y la imagen positiva que tengan los visitantes serán muy importantes para llegar a sumergirse en el mundo de fantasía. Un ejemplo puede ser el momento en que un visitante cruza el arco para entrar a Hogsmeade', donde se representa el mundo 


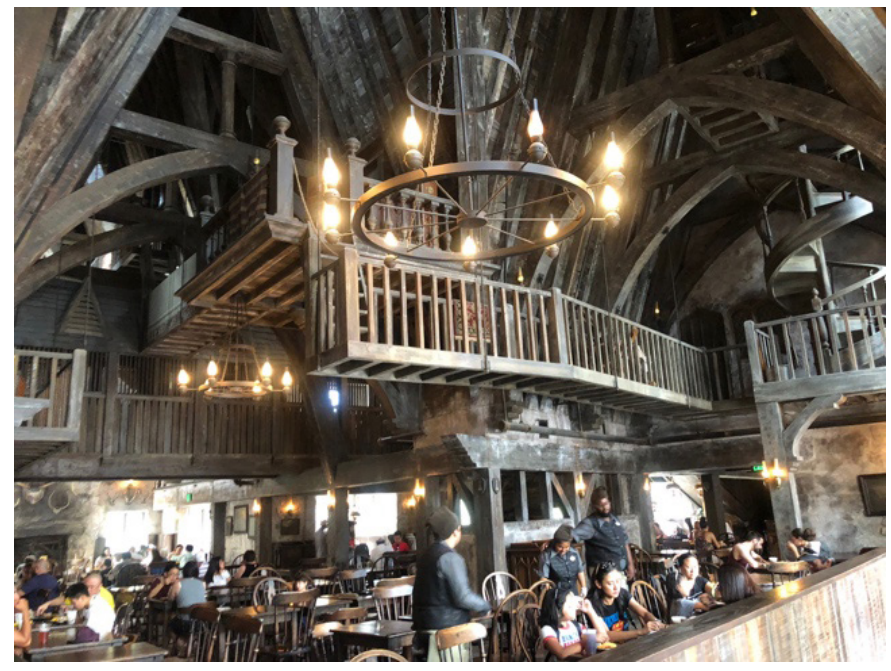

Figura 1. Restaurante Three Broomsticks, Los Ángeles, California. 2018. Fuente: archivo fotográfico de Elisabet Fonts.

de Harry Potter de Universal Hollywood de California. Es como un portal mágico que da acceso al mundo de la ilusión. Para salir de Hogsmeade se debe volver a pasar por el portal. Así que, dicho portal tiene un significado. En el momento que entra el visitante sabe que accederá a la zona de Harry Potter y en el momento que sale se trasladará a otro mundo de fantasía lejos de los dominios de Hogwarts².

Por lo tanto, todo lo que se podrá ver en el entorno debe seguir con la temática del joven mago. Todos los detalles son importantes, incluso en el restaurante Three Broomsticks. En el momento que entra el público verá que hay gente pelirroja o rubia, alta y delgada atendiendo a sus clientes. La luz jugará un papel fundamental, servirá para trasladar al huésped al interior de la película, será reconocible por los fans y se replicará en las estancias cerradas. Wong y Cheung (1999) proponen unos puntos clave para la realización de un contenido temático dentro de un parque:

- El parque puede optar por hacer una única temática, como es el caso de Warner Bros.

- También se puede presentar a través de diferentes subtemas como es el caso de Disneyland. Así, aparecerán diferentes zonas o mundos que complementen al tema principal como Main Street Usa, Tomorrowland, Fantasyland, Adventureland y Frontierland.

- Otra forma puede ser mediante temáticas temporales muy marcadas por campañas. Por ejemplo, en Halloween se transforma todo el parque Universal Port Aventura para convertirlo en un pasaje del terror. Todas las decoraciones, personajes y festividades sólo se hacen en un corto espacio de tiempo.
Clavé (2005) enfatiza que la temática se puede tratar bajo tres puntos de vista:

Temática como argumento. Como hemos comentado anteriormente, una temática requiere que tenga una buena narrativa, es decir, una buena historia de fondo que atraiga al huésped y confluya con lo que está viviendo. Por lo tanto, se ve afectado en la totalidad, ya sea en las atracciones que dispongan, en la elaboración de la decoración, espacios, etc. Es importante que tenga un significado, es decir, el concepto del parque y un significante que hace referencia a la determinación. Todo esto hace que de sentido a toda la estructura del parque. Cada matiz será importante para darle sentido a la totalidad del argumento. Como describe Swartzman: "Tematizar tiene que ver con el uso del relato, el espectáculo y la tecnología en la creación de un ambiente de entretenimiento que promueve una fantasía, localización o idea" (1995, p. 25). Se puede decir que la temática apela a los sentimientos de los huéspedes, y, por otro lado, ellos quieren que la temática les haga vivirlo como si fuera auténtica. El argumento sentimental, Clavé (2005), se representa mediante la arquitectura, las formas y los volúmenes de las baldosas, siendo importantes todos y cada uno de los detalles. Es por ello por lo que Brill (1993) argumenta que la elección de la temática es una parte fundamental, pero la materialización física debe ser como algo real, ya que forma parte de la totalidad del mundo.

- Temática como fundamento organizativo. Ren (1998) opina que para que la temática tenga éxito hacia el huésped, la organización es un factor muy importante. Los trabajadores deben vestirse con ropa que ayude a la tematización, y es muy importante que nunca se dejen ver con su ropa normal, ya que puede sacar de la inmersión y parecerían un visitante más en lugares o zonas donde no deberían estar, como por ejemplo organizando las colas de las atracciones. Es importante que todos se muestren con sus uniformes dependiendo del mundo o de la atracción, cada una de las cuales debe tener vestuario creado específicamente ya sea con conceptos asociados a la temática o bien con uniformes sacados directamente de esta. Por ejemplo, en el mundo de Futureland de Disneyland en la atracción de Star Wars los trabajadores visten con la ropa que llevan en los pilotos rebeldes en las películas. Esto dará continuidad a la inmersión y a la temática. Algo que también se debe tener muy presente para que los visitantes puedan disfrutar de un parque temático es que es necesario que haya una muy buena organización. Cuanto mejor sea, mejor será la experiencia. Esto llevará a que, si el proceso tiene éxito, mayores serán los ingresos y la productividad de parque. Para ello se requiere que la música y las imágenes motiven a los huéspedes a que puedan ir a zonas concretas del parque. Por lo tanto, un elemento también muy importante es que regulen 


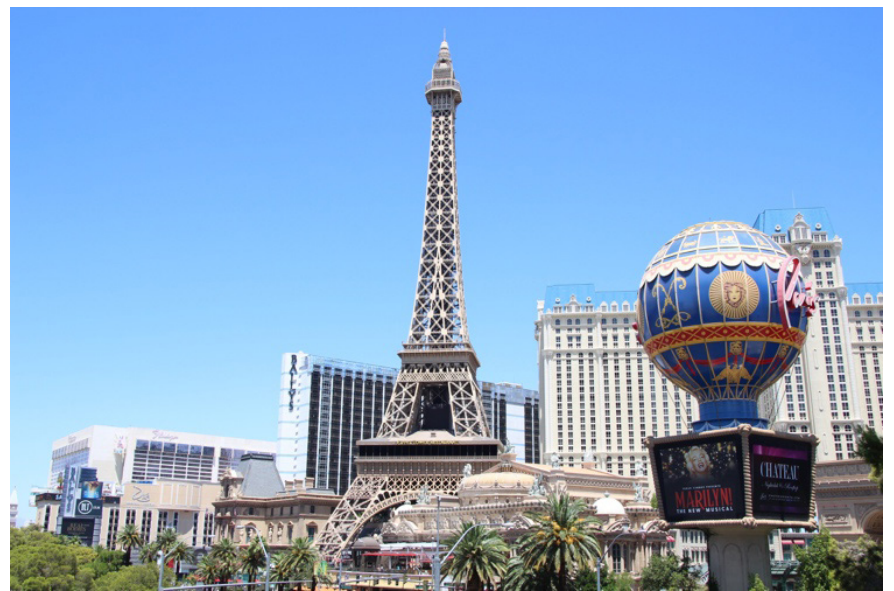

Figura 2. Las Vegas, Nevada. 2018. Fuente: archivo fotográfico de Elisabet Fonts.

el ritmo de afluencia.

- Tema como estrategia de marketing. La capacidad de la atracción se verá afectada según la temática o las diferentes temáticas. Si hay una singularidad temática condicionará al simbolismo de cada tema. Sin embargo, Clavé (2005) expone que el contenido puede ser administrado de diferentes formas.

Chaspoul (2001): apunta que se puede tematizar a partir de un único tema. Por ejemplo, los casinos de Las Vegas. En el caso de los casinos temáticos tienen una estructura a nivel de arquitectura y diseño. Como es el caso de París de Las Vegas. Es una ciudad que tiene atributos muy marcados como es la riqueza, moda, glamour, belleza, romanticismo o sofisticación. Por lo tanto, emplean todos y cada uno de los elementos y los utilizan para sumergir al huésped en su hotel. En segundo lugar, monumentos emblemáticos de París cómo la Torre Eiffel, el Arco de Triunfo y la Fuente de los Mares de la plaza de la Concordia. Con todo ello, se construye en medio de la ciudad y junto con los acordeonistas que ambientan en el casino, da la sensación de estar en la ciudad de la luz. Un elemento que han implementado es que en la Torre Eiffel es posible reservar

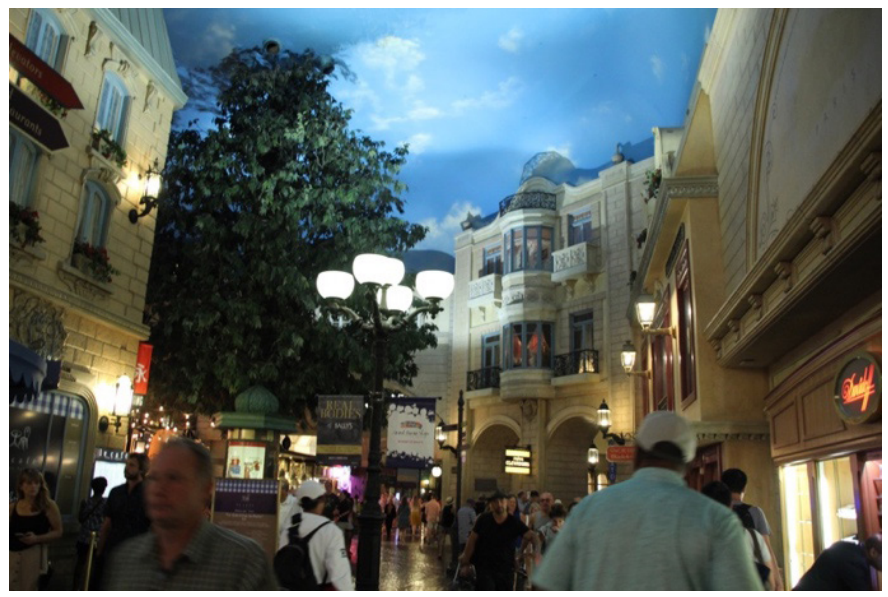

Figura 3. Las Vegas, Nevada. 2018. Fuente: archivo fotográfico de Elisabet Fonts. mesa en un restaurante. Al igual que en Francia, cenar allí es un símbolo de romanticismo. En Las Vegas también lo es. Por este motivo el visitante necesita reservar para poder ir a cenar, ya que lo habitual es no encontrar mesas disponibles en el restaurante. Por otra parte, también han replicado el famoso ascensor para poder subir a la torre. No es posible ver la ciudad de París, pero sí las grandes vistas de Las Vegas Strip.

El exterior es realmente impactante, pero también lo es el interior que simula las calles de París. Los rótulos, la música, la ambientación, la disposición de tierra, las farolas, el color de la luz, la distribución del espacio, los árboles... Todos los elementos son muy importantes para trasladarte a Francia. Por muy insignificante que parezca los aseos también juegan un punto muy importante. Intentan que el huésped no salga mentalmente del espacio inmersivo. El rótulo está en francés Toilette ${ }^{3}$, el diseño interior traslada al visitante al arte modernista de los finales del XIX y principios del siglo XX. Conocido como la Belle Époque ${ }^{4}$, movimiento artístico inspirado en la naturaleza con elementos de la revolución industrial como es el acero y el vidrio.

Pero como en todos los hoteles temáticos de Las Vegas, el diseño y todas las líneas arquitectónicas tienen el mismo epicentro: el casino. Es fácil poder acceder para cualquier visitante que no se hospede en los hoteles, ya que todas las entradas siempre desembocan en los respectivos casinos, y todo lo que le envuelve confluye alrededor del juego. Los espacios más

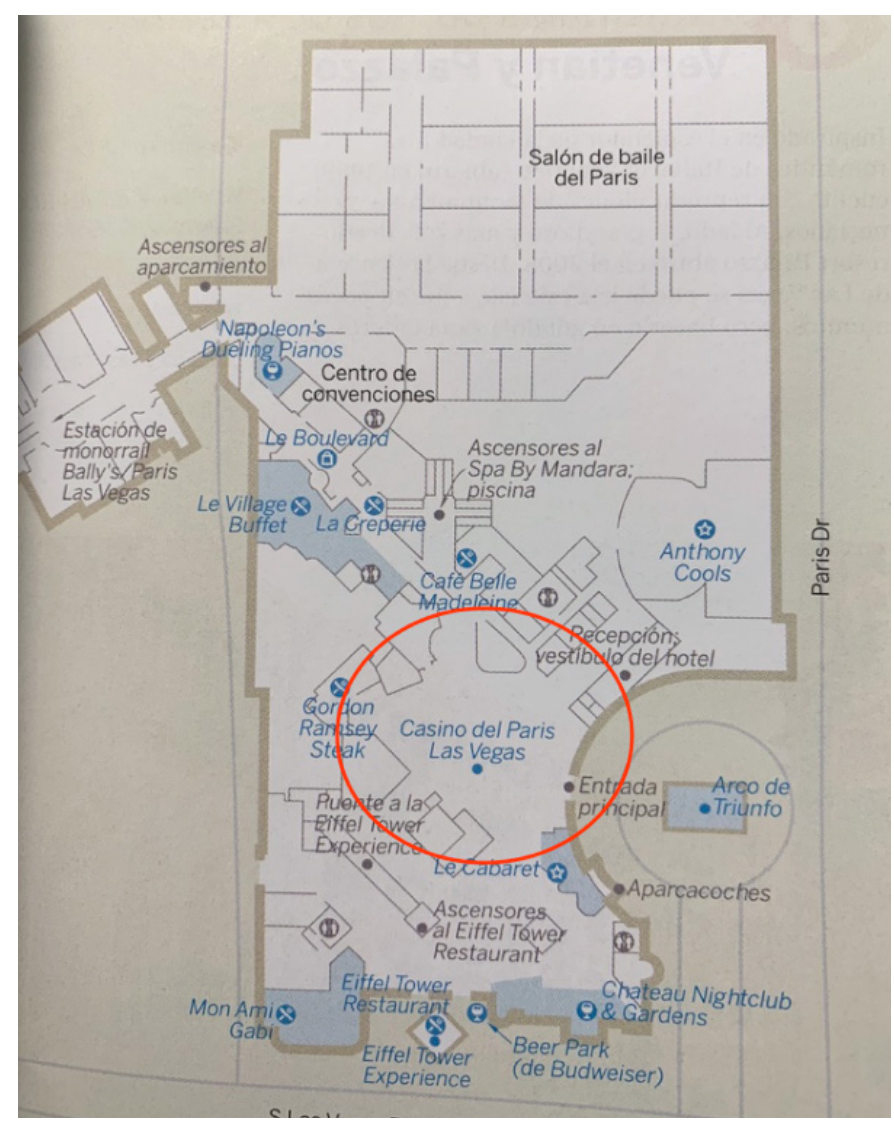

Figura 4. París, Las Vegas, Nevada. 2018. Fuente: Geo Planeta. 
amplios se encuentran allí. Y alrededor conviven restaurantes, salas de espectáculos y las habitaciones del hotel. Es fácil entrar y ver las famosas tragaperras de todo tipo de temáticas, pero, por otro lado, puede parecer difícil encontrar alguna experiencia o una tienda en concreto si no se sabe dónde está. Como hemos mencionado anteriormente, todo está pensado y diseñado para el consumismo. Lukas (2012) comenta que la tematización puede ser una manera de contar una historia ya vivida dentro de un espacio.

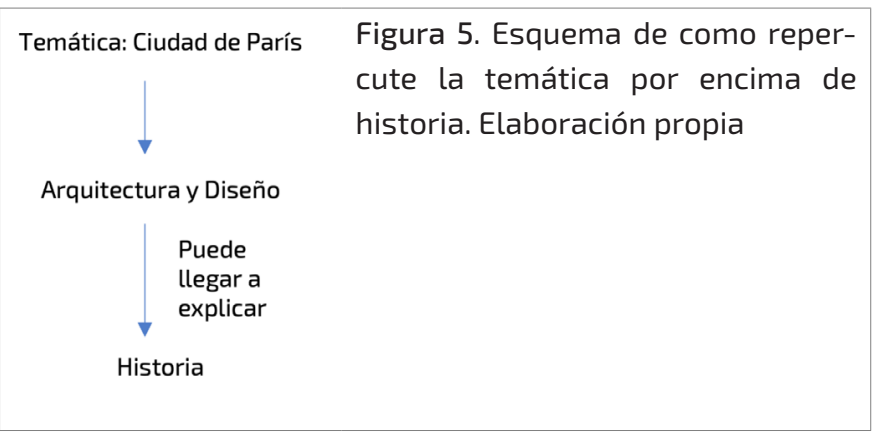

En el caso de los casinos la temática o ciudad influyen sobre el diseño y la arquitectura de este. Es decir, como en el caso del hotel que se está analizando es París, todas las características principales de la ciudad parisina deben verse reflejados en él. Por otra parte, también los estereotipos más típicos parisinos de la ciudad. Por lo tanto, todo afecta tanto a la arquitectura como al diseño. Ya sean las formas, rótulos, adoquines, colores, texturas, la ropa de los empleados, entre otros. Inicialmente el huésped sentirá como si estuviera dentro de París. Por tanto, la historia se verá influenciada por todos estos elementos que se han mencionado.

Según Wong y Cheung (1999), la tematización de estos espacios tiene como beneficio los siguientes puntos:

- Crear una temática donde el visitante tenga la percepción de que es de calidad.

- Incrementar que los huéspedes vuelvan y que frecuenten el parque.

- Proporcionar más valor añadido a parque.

- Los productos que se vendan en el parque son muy importantes para el consumo.

- Cuánta mejor aceptación tenga el parque más grande será su reconocimiento.

Se puede decir que tematizar no implica sólo escoger un tema, o simplemente seleccionar un tipo de decoración para un lugar en concreto. Tematizar implica mucho más. Cada detalle es muy importante, y esto provoca que se refuerce la inmersión en los parques temáticos. Clavé lo describe como "tematizar es, de hecho, un proceso de construcción física y social de un tipo de realidad que, siendo imaginaria, magnifica las características de la sociedad contemporánea" (2005, p. 120). Para ello, todo tipo de arte y ciencia unen sus fuerzas para crear un lugar único e inmersivo. Archer apunta que tematizar significa "intentar construir la realidad de las cosas o de los sitios sobre la base de la nostalgia y la amnesia, o la memoria y el olvido parciales" (1996, p.50). Según Wong y Cheung (1999), algunas temáticas que han utilizado los parques de atracciones son las siguientes:

\begin{tabular}{|c|c|}
\hline Tipo & Atributo \\
\hline Aventuras & $\begin{array}{l}\text { Excitación y acción } \\
\text { Miedo } \\
\text { Misterio } \\
\text { Emoción }\end{array}$ \\
\hline Futuro & $\begin{array}{l}\text { Avances en la sociedad y la tecnología } \\
\text { descubrimientos } \\
\text { Exploraciones de la ciencia y la tecnología } \\
\text { Láser } \\
\text { Robot } \\
\text { Ciencia } \\
\text { Ciencia ficción }\end{array}$ \\
\hline Internacional & $\begin{array}{l}\text { Sabores del mundo } \\
\text { Ciudad internacional } \\
\text { Réplicas en miniatura } \\
\text { Lugares escénicos } \\
\text { Exposiciones universales }\end{array}$ \\
\hline Naturaleza & $\begin{array}{l}\text { Animales } \\
\text { Muestras florales } \\
\text { Jardines de horticultura } \\
\text { Paisajes } \\
\text { Vida marina } \\
\text { Bellezas naturales } \\
\text { Océano } \\
\text { Vida salvaje }\end{array}$ \\
\hline Fantasía & $\begin{array}{l}\text { Animación } \\
\text { Personajes de dibujos animados } \\
\text { Fantasías infantiles } \\
\text { Parques de juego infantiles } \\
\text { Cuentos de hadas } \\
\text { Magia } \\
\text { Creencias } \\
\text { Mitos y leyendas }\end{array}$ \\
\hline $\begin{array}{l}\text { Historia y } \\
\text { cultura }\end{array}$ & $\begin{array}{l}\text { Aborígenes } \\
\text { Autenticidad } \\
\text { Patrimonio cultural } \\
\text { Reclamos étnicos } \\
\text { Fiebre del oro } \\
\text { Ambiente histórico }\end{array}$ \\
\hline Cine & $\begin{array}{l}\text { Espectáculo del salvaje oeste } \\
\text { Comedia } \\
\text { Películas } \\
\text { Show business } \\
\text { Stunt show }\end{array}$ \\
\hline
\end{tabular}

Tabla 1. Temáticas y atributos utilizados para desarrollar parques temáticos. Wong y Cheung (1999).

Como podemos observar en la tabla 1 hay diferentes tipos de temáticas con diferentes atributos. En el caso de los parques con temática Disney tienen una clara temática de fantasía 
donde se rinde un atributo ésta, a sus personajes carismáticos y mágicos. Como también el arte de dar vida a personajes mediante la animación. En el caso de Universal tiene una clara temática muy focalizada en el mundo del cine y los espectáculos. Aunque tanto el parque de Disney como Universal tienen como trasfondo el mundo del cine, lo tratan de maneras diferentes. Universal se centra más en realizar espectáculos específicos del mundo del cine, como por ejemplo escenas de acción de riesgo. Por otra parte, el parque gira en torno a películas creadas por la propia productora o temáticas cedidas como es el caso de la serie The Walking Dead o el mundo mágico de Harry Potter. Disney rinde un claro homenaje a la animación 2D y 3D. En el caso de Animal's Kingdom, situado en Florida, se podría decir que Disney ha creado un parque donde la protagonista es la propia naturaleza.

Milman (2001) presenta en la siguiente tabla una clara tendencia temática en los parques que puede afectar para futuras aperturas en Estados Unidos.

\begin{tabular}{|l|l|}
\hline \multicolumn{1}{|c|}{ Contenidos } & \multicolumn{1}{|c|}{ Escala de 1 al 5 } \\
\hline Aventuras interactivas & 4,18 \\
\hline Fantasía y misterio & 3,82 \\
\hline Cine y televisión & 3,69 \\
\hline Ciencia ficción / futuro & 3,6 \\
\hline Espacio & 3,45 \\
\hline Naturaleza / ecología & 3,44 \\
\hline Educación & 3,32 \\
\hline Temas estacionales & 3,2 \\
\hline Deportes & 3,11 \\
\hline Temas de novelas & 3,06 \\
\hline Alimentación & 3,06 \\
\hline Ciencia & 3 \\
\hline Diversidad cultural y demográfica & 2,92 \\
\hline Historia & 2,73 \\
\hline Transporte & 2,68 \\
\hline Temas étnicos & 2,67 \\
\hline
\end{tabular}

Tabla 2. Se presentan las nuevas tendencias de los ciudadanos estadounidenses para la creación de nuevos parques temáticos. Milman (2001).

Como podemos observar la escala de 1 al 5, el 5 representa el máximo interés para futuras temáticas en los parques. En cambio 1 representa los menos interesantes. Milman (2001) muestra cómo las aventuras interactivas tendrán mucho peso, ya que cada vez más los visitantes tienen ganas de formar parte de la acción. Quieren sentir que ellos son los protagonistas y actuar ellos mismos. Actualmente, se presentan espacios específicos donde mediante la realidad virtual, el visitante forma parte de la trama e interactúa con su entorno. Cabe destacar que los temas étnicos, como la historia, son menos interesantes para los consumidores y por ello es interesante la combinación de estos temas para atraer al público, como por ejemplo en la Fortaleza Real de Chinon en Francia, dónde el visitante puede ver elementos extras mediante realidad aumentada, así como también interactuar virtualmente con catapultas o cañones de la fortaleza. Como hablaremos más adelante, la empresa de animación de Walt Disney pospuso construir un parque donde la temática principal fuera la historia de los Estados Unidos. Esta temática causó tanto rechazo en la sociedad americana que, finalmente, el parque fue desestimado.

Todos estos factores deben tenerse en cuenta, ya que las visitas se verán incentivadas dependiendo del mundo y la temática que se haya creado. McClung (1991) afirma que el tema es un factor decisivo en el momento de ir a visitar un parque temático u otro. De ahí que un tema que tenga mucha riqueza visual o sea un producto transmedia el público se verá seducido para ir a visitarlo. Por ejemplo, en el caso de Wizarding World de Harry Potter, los fans de Harry Potter tendrán un motivo para ir al parque Universal para poder disfrutar del espectáculo de noche, las tiendas y la interactividad que ofrecen, el restaurante, las atracciones etc. Según Clavé (2005), para que un tema tenga éxito debe formar parte de la memoria colectiva del público objetivo.

\section{El fracaso de California Adventure}

Para desarrollar un parque temático, hemos podido ver que se tiene que atrapar a los visitantes con una buena historia. Esto no es algo fácil. Clavé (2005) opina que los parques de atracciones que se plantean forman parte de la cultura social. Por tanto, se plantea que el paisaje se enlaza directamente a una localización en concreto.

En 1993, Walt Disney Imagineering ${ }^{5}$ desarrolló el concepto de un nuevo parque temático que celebraba la historia de Estados Unidos. Situado a $75 \mathrm{~km}$ al oeste de Washignton D.C., Llevaba como nombre Disney 's America. En el parque se podría vivir diferentes experiencias que marcaron la historia de Estados

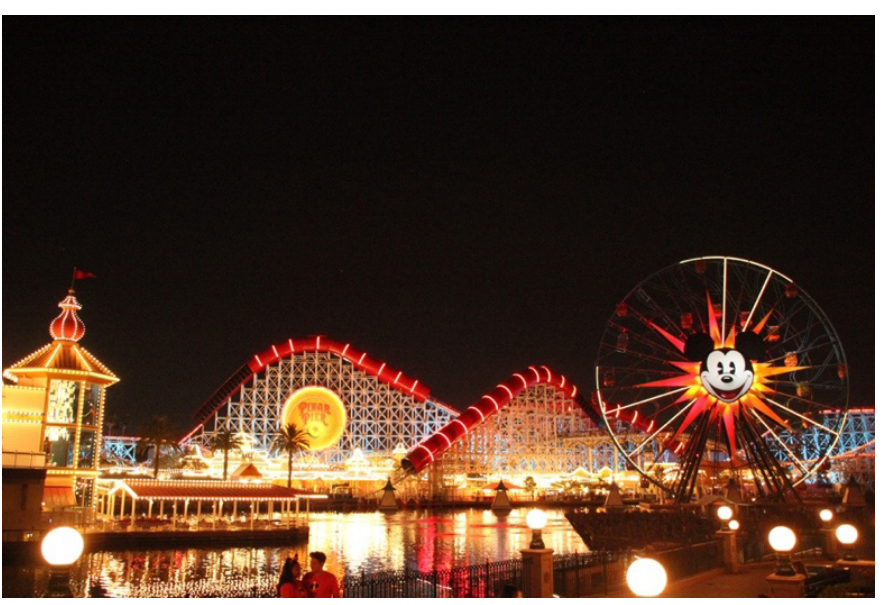

Figura 6. California Adventure, California 2018. Fuente: archivo fotográfico de Elisabet Fonts. 
Unidos. El parque tendría diferentes mundos donde se pudiera revivir estos hechos históricos. Uno de los conceptos visuales que desarrollaron fue vivir una lucha área de la 2a Guerra Mundial. También se diseñaron montañas rusas, como, por ejemplo, la dedicada al progreso de la Revolución Industrial, que se explicaría mediante un vagón de la mina. Por otro lado, la expedición de Lewis y Clark, donde los huéspedes subirían en una balsa de río y vivirían una aventura. Iwerks (2019) da voz al exdirector y ejecutivo de The Walt Disney Company, Michael Einser ${ }^{6}$ quien comenta que la idea principal era que los jóvenes se sintieran atraídos por la historia de su país a la vez que se divirtieran. Sin embargo, el proyecto no se llevó a cabo, ya que los vecinos reclamaron que no se construyera el parque y se decidió dar un paso atrás.

Michael Einser tenía muy claro que quería construir un segundo parque en Anaheim, situado en Los Ángeles. Las infraestructuras de la ciudad fuera de las paredes de Disneyland no eran muy buenas, ya que estaba en total decadencia y no causaba una buena impresión para los visitantes. Algo que se podía observar era que la mayoría de los visitantes destinaban un solo día para pasarlo en Disneyland. Es por ello por lo que uno de los primeros cambios que se propuso fue desarrollar un diseño urbano. Como referente tendrían el parque Walt Disney World, situado en Florida, reconocida como la capital mundial de las vacaciones. La prioridad fue construir un hotel de lujo, un centro comercial, una estructura de aparcamiento y una buena entrada en la autopista. Después de trabajar durante cuatro años seguidos, en Walt Disney Imagineering no sabían qué desarrollar en el segundo parque. Iwerks (2019) muestra que se hicieron propuestas para desarrollar la misma idea de parque de EPCOT ${ }^{7}$, pero situado en la costa oeste. Para ello, surgió la idea de ubicarlo en California.

Michael Einser quiso acelerar el proceso para poder construir lo más rápido posible. Insistió en que el parque representara una visión vanguardista del sur de California. Por este motivo, se quiso exaltar los diseños que recordasen los tópicos como el glamour de Hollywood, la cultura de playa, así como también la belleza característica del estado. Paradise Pier estaba pensado como un parque de atracciones, así como un paseo marítimo. Es por eso por lo que reflejaba la nostalgia con la vieja Coney Island, algo que Walt Disney no quiso en el momento que creó Disneyland. A consecuencia de ello, rompió con toda la cultura Disney. Tampoco había ninguna barrera que separara del mundo exterior que Walt Disney trabajó para que los visitantes se sintieran totalmente inmersos.

Tim Delaney, director creativo de Walt Disney Imagineering, comentó que algo que necesitaban que representara California era un elemento emblemático. Por lo tanto, colocaron en la entrada el puente de Golden Gate junto unas letras muy llamativas donde se podía leer la palabra California. Iwerks (2019) muestra cómo Kevin Rafferty, creativo de Walt Disney Imagineering, opinaba que no coincidía con los diseños de un parque temático, porque algunos de los elementos se podían ver en un centro comercial. Por lo tanto, las decoraciones y todo lo que giraba entorno a ellas no estaba a la altura de Disneyland y no conseguían reforzar la temática del parque.

Como es el caso de los últimos parques que Disney realizó, California Adventure está ubicado en Estados Unidos. Ingram (2016) comenta que la temporalidad que se presenta en California Adventure es bastante diferente a lo que Walt Disney hizo en su parque de atracciones. En este parque, han preferido apostar por estructuras que simbolicen algo para el visitante. Para ello, se basan en un concepto "retro-futurismo" que simbolizan los diferentes reinos psicológicos de los huéspedes.

Disney California Adventure abrió sus puertas en febrero de 2001 con baja acogida. Paul Pressler, presidente de Disneyland de 1994 a 1999, opinaba que era un parque pequeño y, comparándolo con Disneyland, la mayoría de los visitantes podría pensar que sería igual que el original, tendría el mismo número de atracciones y su gran extensión. Pero esto no fue así. Iwerks (2019) asegura que en Disneyland acudían 13 millones de personas al año. En cambio, el nuevo parque estaba pensado para 5 millones. Esto suponía un gran dilema para el consumidor, ya que la entrada para los parques era la misma y era la tercera parte de parque original, por lo que California Adventure no podía competir. Por otra parte, era un parque que se podía visitar en un día. Sin embargo, sólo venían suscripciones anuales a los huéspedes de los hoteles de Disney. Algo que no gustó al público fue que tenían que pagar dos parques de atracciones. Además, Iwerks (2019) explica cómo el precio representaba un obstáculo, ya que era bastante elevado para ser un parque que, según el público, consideraba que "era inferior" en Disneyland, ya que el primer parque consta de 60 atracciones y provoca que California Adventure sea minúsculo. Esto se debe a que ofrecía menos atracciones y era más pequeño.

Sin embargo, en cuanto abrieron las puertas del nuevo parque esperaban una reacción diferente por parte de público. La nostalgia utilizada en el parque clásico junto con el posmodernismo restaurado no funcionó en California Adventure. Eso también pasó años atrás cuando se abrieron las puertas de Walt Disney World en Florida. Perdió mucho atractivo para una sociedad que era posterior a la Guerra Fría. En este momento, la gente buscaba otras emociones y sensaciones.

Según Daniel Jue, creativo de Walt Disney Imagineering, California Adventure fue una decisión empresarial. Por este motivo, no se llevó a cabo algo más creativo o similar en el parque original. El ejemplo fue el segundo parque que se construyó en Paris. Se consideró que era una necesidad. Sin embargo, se edificó muy rápido y lo más barato posible. El motivo de la construcción tan rápida y en último momento fue porque Disney estaba obligado por contrato a construir un segundo parque temático en París. Si no lo edificaban perderían el terreno que les había cedido el gobierno francés. 
La mayoría de las atracciones que se podrían ver serían importadas, es decir, no habría muchas novedades y también sería considerado el parque Disney más pequeño de todos. No era de extrañar que se convirtiera el parque con menos afluencia de todos.

\section{Bob Iger: Avanzar quiere decir corregir el pasado}

El 1 de octubre de 2005 Bob Iger fue nombrado el nuevo presidente de The Walt Disney Company. Quería trabajar tres puntos fundamentales de la compañía:

\section{- Expansión internacional.}

- Nuevas tecnologías.

- Contenido creativo y fresco.

Iwerks (2019) comenta que Bob observó que California Adventure no estaba a la altura de un parque Disney. Una de las grandes preguntas importantes era: ¿se podrá arreglar? ¿Costaría mucho dinero?. Lo que era evidente para Bob era que significaría una gran inversión. Es, por este motivo, que supondría todo un reto. Se consideró que el parque era un fracaso desde los cimientos. Es decir, no había temática que enganchara al público y tampoco era atractivo. Y, por tanto, se tenía que arreglar. En el contexto de crisis financiera del

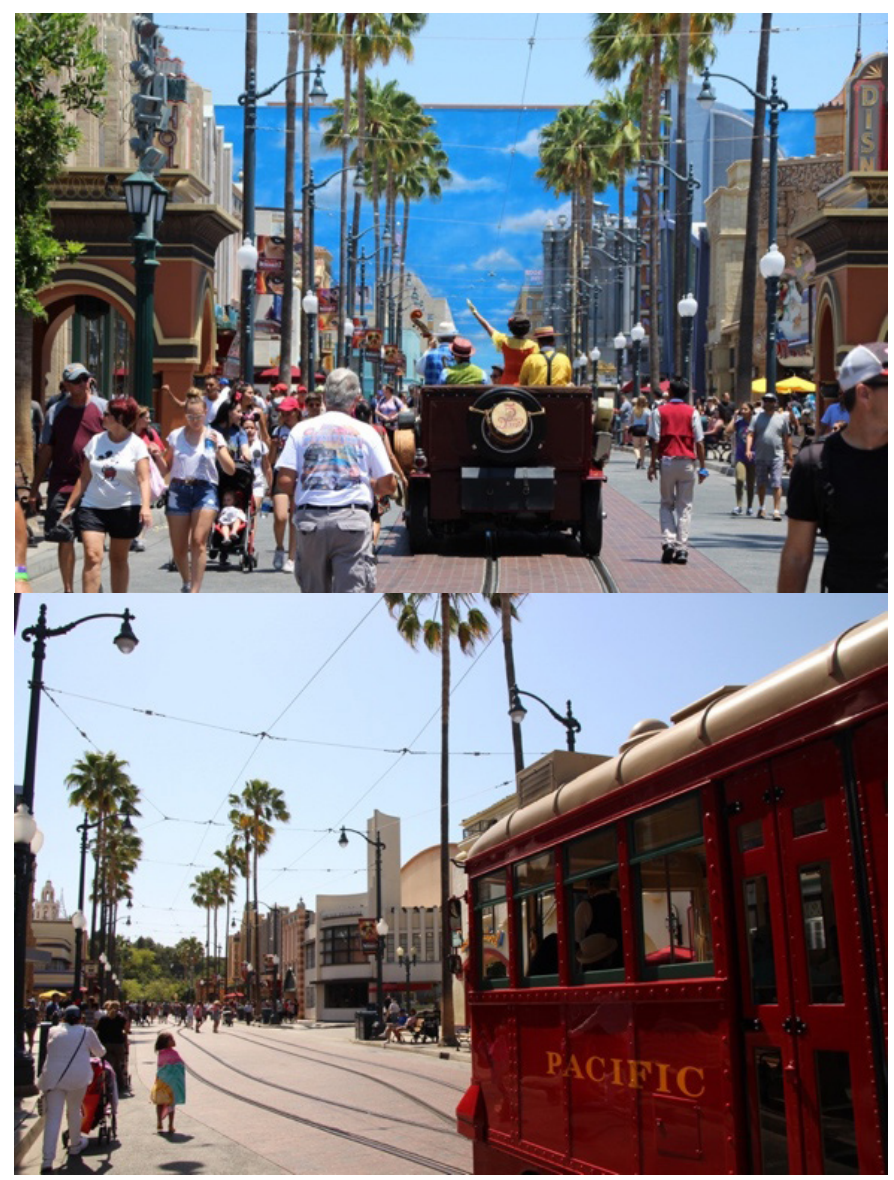

Figura 7. California Adventure, California 2018. Fuente: archivo fotográfico de Elisabet Fonts.

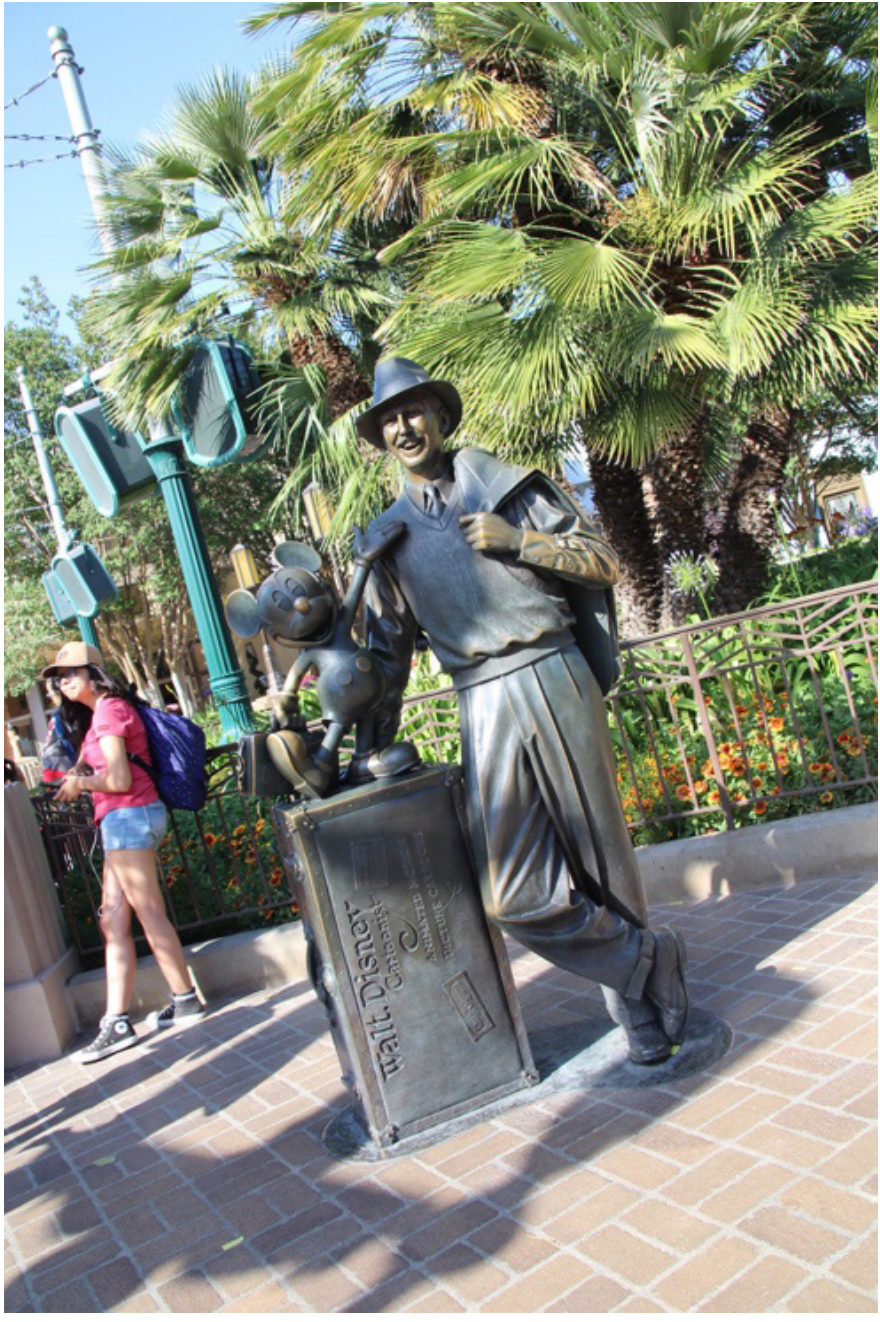

Figura 8. California Adventure, California 2018. Fuente: archivo fotográfico de Elisabet Fonts.

momento, invertir en la reforma del parque se convirtió en un verdadero compromiso, con el objetivo de hacer, esta vez, las cosas bien. Según Bob Weis, jefe creativo de Walt Disney Imagineering (2007-2012), el parque no tenía la sensación de calidez ni tampoco formaba parte de la burbuja Disney. Por este motivo, desentonaba y los visitantes no se sentían cómodos.

Con la llegada del Bob Iger, todo cambió. En primer lugar, una de las cosas que se retiró fue la entrada que tenían con las letras de California y el puente. Iwerks (2019) anota que una de las propuestas que se llevaron a cabo fue abrir todo y tratar la entrada como si fuera la entrada de un pueblo, algo que recordara a Main Street y que explicara la historia de Los Angeles de 1920-1930 cuando el joven Walt comenzó su trayectoria en el mundo de la animación. Sunshine Plaza, la plaza principal de parque, sería lo primero que verían los visitantes junto con una escultura de Walt y su personaje carismático, Mickey Mouse ${ }^{8}$. Era un buen motivo para conectar los dos parques de Disney, ya que en ambos aparece una escultura de Walt Disney. En este caso, pertenecen a épocas diferentes como también los lugares son diferentes. Pero siempre mantienen una conexión 
con su creador y con famoso ratón.

Los nuevos personajes de Pixar aparecerían en la nueva propuesta de parque. Algo que trabajaron para atraer al público es utilizar tecnología para así captar la atención del huésped. Algunos ejemplos son atracciones interactivas Toy Story Midway Mania, donde el público puede disparar a objetivos durante la atracción y recibir una puntuación al final o robots que hicieran cobrar vida a los personajes, como por ejemplo la impresionante carrera en la atracción Radiator Springs Racers donde se pueden ver los personajes de las películas de la saga Cars cobrar vida. Sin embargo, para poder equilibrarlo, Paradise Pier se encargó de dar un punto más nostálgico de personajes clásicos. Según Bob Iger:

El legado aún resulta entrañable, acogedor, aunque entretiene. No hay que deshacerse de él, ni despreciarlo. Pero tampoco hay que idolatrar, porque si idolatras algo, creo que no quieres que nada cambie colocarías todo en vitrinas de museo. Yo no quería eso. Iwerks (2019).

\section{La implementación del mundo en los parques temáticos}

Uno de los factores más importantes en el momento que se crea una inmersión es la creación del mundo. Cuando se habla de mundo inmersivo significa que es el lugar dónde la gente quiere estar. Ya sea un restaurante, un parque temático, hotel o centro comercial, entre muchos. Es un lugar donde la gente disfruta de lo que está haciendo. Para Lukas (2012), se sumergen en dos sentidos fundamentales. En primer lugar, la localización tiene algo en conjunto que provoca el placer de permanecer. Por lo tanto, los sentimientos irán muy relacionados con la inmersión. En segundo lugar, las personas crean una asociación de sentimientos positivos que evocará al cliente a entrar en un mundo creado para él o ella.

El concepto de mundo es muy importante. ¿Pero, como se puede llegar a definir? El mundo, para un parque temático, puede entenderse como parte de la experiencia de entretenimiento, del consumidor y de la marca. Pero para completar un mundo y hacerlo más rico es importante tener en cuenta la experiencia y lo transformante de la misma. En el momento que se diseña una atracción se tienen en cuenta muchos aspectos que son importantes. El mundo que se crea en el entorno más complejo, ya que según Lukas (2012) la creación de un mundo unidimensional puede llegar a ser poco atractivo o sin interés. Otro aspecto importante es la cultura y la historia. Cuanto más rico sea el mundo creado más atractivo será. Por ejemplo, el mundo de Harry Potter está muy detallado y J.K. Rowling conceptualiza la cultura de los magos y su mundo en comparación con la de los no magos o muggles 9 . Por lo tanto, se puede decir que el mundo siempre se está moviendo y no es estático.

En un parque temático existe el concepto de un macro mundo y los submundos que apoyan el macro. Para ejemplificarlo utilizaremos el parque original de Disneyland, California de Estados Unidos. En el momento que el visitante entra en Disneyland California tiene un pasillo principal Llamado Main Street, considerado como el protagonista. Su misión es sumergirte en el mundo Disney y su época. Es como la entrada de un pueblo, pero con un punto de vista nostálgico. Sin embargo, todo lleva al castillo o el símbolo principal. Este elemento principal es el macro mundo.

Por este motivo, siempre vuelves al punto inicial. Ya sea para ver los espectáculos o para pasar de un lado a otro, aunque si es cierto que se puede dar una vuelta. Pero curiosamente la manera más rápida de ir de un lugar a otro es pasando por el punto central o el punto de encuentro. Para ello cuenta, el parque cuenta con diferentes portales que llevan a otros mundos que sirven para enriquecerlo. En el caso de Disneyland Paris aparecen las cuatro zonas temáticas que se ramificaban desde el centro y englobaban todos los intereses de Walt Disney:

- Fantasyland. Es como un hogar para sus personajes animados.

- Tomorrowland. Es la visión y la promesa hacia el futuro.

- Adventureland. Muestra un entorno natural.

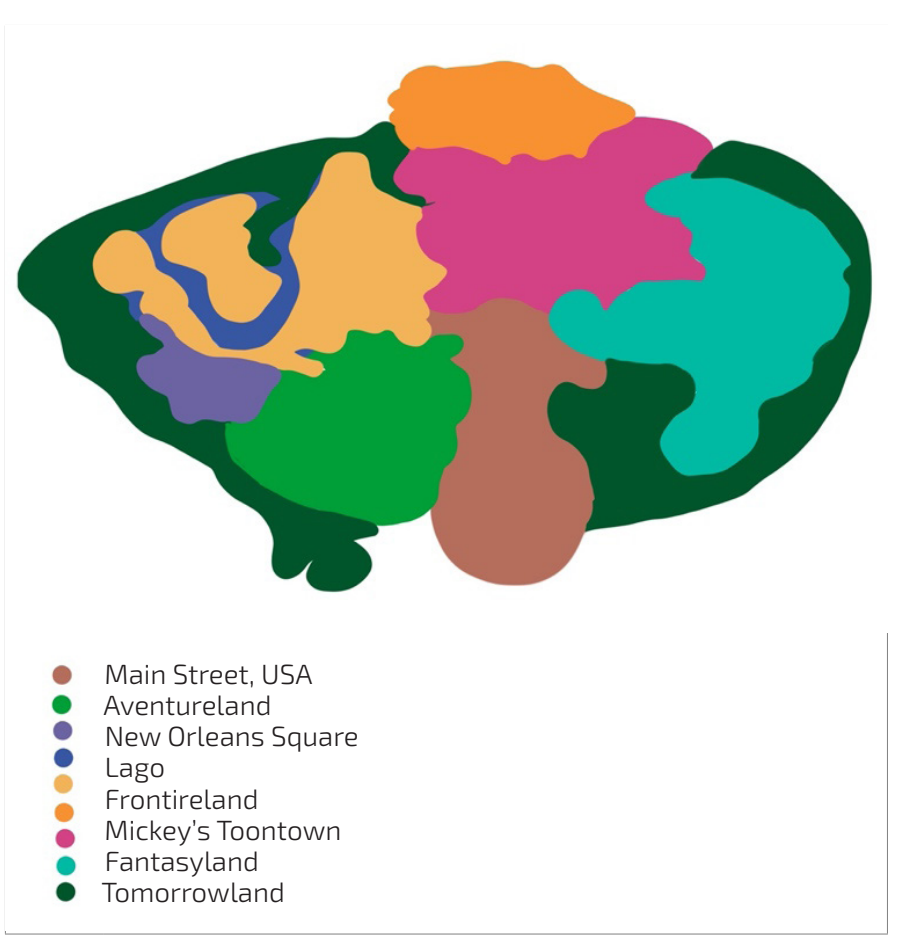

Figura 9. Mapa de Disneyland, California 2018. Fuente: archivo fotográfico de Elisabet Fonts. 
- Frontierland. Representa un espíritu aventurero y de exploración.

Es en este momento cuando el visitante se sitúa en el corazón del parque. Puede ir al portal que más le llame la atención y pasar de un lugar a otro. Sin embargo, todo lo que circunda forma parte del mundo Disney. Es decir, todo lo que rodea forma la totalidad del mundo Disney. Para Lukas (2012), son muy importantes tanto los mundos macros como los micros. Es decir, los mundos que tienen una temática en concreto, como por ejemplo Frontierland en Disneyland, dónde la temática principal es el viejo oeste; y los mundos micros que son los mundos que giran alrededor sus atracciones como Phantom Manor, utilizando una mansión encantada de la época representada en Frontierland. Por este motivo, se deberá prestar mucha atención en cómo se presentan los distintos mundos, ya sea a nivel de decoración, arquitectura, música, distribución del espacio y sus mismas atracciones. Es imprescindible mostrar de una manera clara cómo están distribuidos los elementos, el sentido de la credibilidad y el realismo de todo lo que ven los huéspedes sea tan tangible como en las películas. No importa, por ejemplo, que en el parque Super Nintendo World en Japón sean todos edificios de fantasía. Los huéspedes perciben que están realmente en el mundo de Mario. Ya que hay una clara necesidad de mantener a la gente atraída con el mundo que está visitando.

El mundo que se recrea tiene como objetivo que sea inmersivo y disfrutable para el huésped. Las historias deben de estar relacionadas directamente con la experiencia, ya que estará estrechamente relacionado con la imagen que se llevará éste del parque.

Podemos decir que uno de los aspectos primordiales para los diseñadores de los parques temáticos es el espacio. Lukas (2012) afirma que los diseñadores intentan conectar con el huésped, pero de forma íntima. Es decir, en su interior. En este espacio, apelan a los pensamientos y los sentimientos, así como los secretos más personales. Por lo tanto, se puede decir que los diseñadores crean espacios para que los visitantes se los puedan llevar a casa. ¿Pero, cuando pasa? Cuando ya no están en el espacio puede que surja un tema de conversación posterior e incluso puede que estén muy lejos y puedan llegar a hablar de este espacio. Por lo tanto, la arquitectura, el color, la luz y cualquier detalle hará que la experiencia sea recordada. A continuación, se exponen los cuatro niveles de detalle de Walt Disney, Iwerks (2019).

- Primer nivel de detalle: Estás en el campo, puedes mirar sobre los árboles y ver la iglesia.

- Segundo nivel de detalle: Entras en una ciudad y acabas de llegar a Main Street. Así que puedes ver la zona de aparcamiento, la carretera, la media, los árboles, los bancos.

- Tercer nivel de detalle: Estás parado en una acera y el huésped ve una casa bonita. Si se acerca podrá ver todo tipo de detalles como puede ser: el color, la textura, los materiales, la escala, el estilo arquitectónico ...

- Cuarto nivel de detalle: Te diriges a la puerta principal, coges el pestillo o picador, y la usas para llamar a la puerta y sientes la temperatura del metal, la textura que tiene, si está deformado o no, si está pintado, si la pintura está un poco desconchada.

Para poder crear un mundo inmersivo no es necesario que tenga que ser exageradamente grande. Uno de los factores más importantes es que el cliente quede seducido o comprometido con el mundo. Sea la temática que sea, el objetivo principal es crear un lugar para ser disfrutado. Por lo tanto, es importante que la creación del espacio inmersivo se relacione directamente con la experiencia directa vivida por el huésped.

\section{El éxito social de la narrativa en los parques temáticos}

Cualquier storyteller ${ }^{10}$ sabe que parte del éxito depende del conocimiento que tengan los huéspedes. Por eso siempre los medios de comunicación tradicionales intentan medir el éxito mediante la audiencia o el conocido como share ${ }^{11}$. Es por ello, que el éxito social es un factor clave para que las puertas de los parques temáticos no se cierren. Hollywood es la máxima beneficiada, ya que hace sentir a los visitantes como si entraran en diferentes escenas de diferentes películas. Como se ha podido observar, los parques temáticos aún mantienen o conservan los motivos de las antiguas ferias, carnavales, literatura infantil, etc. Apelando siempre a la cultura popular que es la que provoca más aceptación. Zins (1993) realizó una clasificación dividida en cuatro puntos, donde mostraba cómo se consolidó el incremento y el desarrollo de los parques temáticos.

- Las temáticas que se pueden encontrar en los parques es algo que mueve a la población y despierta el interés y la curiosidad.

- El sistema de valores de la sociedad cambia, y es por ello, el nivel de instrucción cada vez es más exigente y esto también se aplica al ocio.

- La tecnología es un aliciente para que la sociedad quiera ir a los parques.

- La experiencia llena los visitantes de diferentes experiencias. Y ofrece la posibilidad de hacer una pequeña salida de 


\section{corta duración.}

Sin embargo, Zins (1993) expone que los puntos que se han mencionado también pueden tener sus puntos en contra que pueden afectar el desarrollo de las diferentes actividades:

- La abundancia entre los diferentes productos temáticos que se ofrecen desde diferentes puntos de consumo como puede ser los parques, museos, lugares de interés, etc.

- La afluencia de alternativas que van dirigidas al ocio o la educación, la vinculación con las nuevas tecnologías o los medios de comunicación como turismo virtual, internet, la televisión.

- La fuerte demanda de experiencias únicas entre determinados sectores.

- En la sociedad tan rápida que se vive en la actualidad puede quedar obsoleto rápidamente.

Clavé (2005) dice que los parques luchan por singularizarse entre ellos. Es por ello, que dedican todas sus fuerzas a desarrollar imágenes muy mediáticas. El marketing es una gran herramienta para poder mover todo esto. HTR (1999) opina que en Europa algo que se valora mucho en los parques temáticos son las montañas rusas, el agua, los contenidos que tienen una finalidad educativa, la naturaleza y la animación virtual. Es por ello, que los parques no dejan de estar focalizados a un público en concreto.

Wootton y Stevens (1994) enumeran 10 tendencias sociales que son clave para el impulso de la actividad en los parques según IAAPA ${ }^{12}$.

- Cocconing. El consumo doméstico como la televisión y los juegos provocan un gran reto para incentivar que los consumidores salgan de su casa y se desplacen.

- Fantasy Adventure. Los visitantes quieren evadirse de la rutina del día a día. Pero en el momento que consumen no quieren arriesgarse o si lo hacen el riesgo siempre es mínimo.

- Small indulgences. Económicamente es muy importante este factor, ya que buscaran la manera que la experiencia sea lo más económica posible.

- Ergonómicos. Todos los usuarios, quieren ser reconocidos de manera individual. Esto motiva las empresas hacer cada vez más experiencias únicas.

- Vigilant consumer. Los visitantes demandan cada vez más responsabilidad por parte de las marcas, ya que muchas veces se les ha embaucado mostrando una publicidad falsa. Es por este motivo, que los consumidores tienen tendencia a desconfiar de las grandes franquicias o marcas por el miedo de ser estafados.

- Staying alive. La sociedad tiene mucho cuidado de su salud y de su alimentación.

- Ninety-nine lives. Como cada vez hay menos tiempo, los consumidores buscan expandir el tiempo gracias a la flexibilidad y así pueden invertir su tiempo para desarrollar otras actividades.

- Cashing out. Tener cada vez más trabajo excesivo por parte de las empresas provoca que las personas se cuestionen y valoren más vida más simple. Por tanto, se valorará además una cultura no urbana.

- Down ageing. Hay una clara tendencia a preservar más la juventud y una clara cultura de su cuerpo.

- SOS (Save our Society). La calidad de vida, la educación, los valores éticos son factores que preocupan a la sociedad y eso hace que cada vez se valore más.

La tecnología es un factor clave para el desarrollo para los parques temáticos. Formica y Olsen (1998) apoyan esta teoría, pero también enfatizan la demografía como un factor clave, ya que cada vez el sector que los consume es más diverso. En el momento que Walt Disney abrió sus puertas a su primer parque estaba focalizado en las familias. Pero ahora todo esto ha cambiado y se ha hecho un cambio de paradigma. Es por ello, que las grandes empresas han aumentado el segmento potencial. Para Clavé (2005), los parques que sobreviven son los que se han convertido en verdaderos centros de entretenimiento que son polivalentes, donde se incluye los restaurantes especiales, teatros, instalaciones deportivas, escenarios para espectáculos y platós donde se puedan producir películas de cine, como el caso de Universal.

\section{Conclusiones y líneas de futuro}

Los parques temáticos son como una extensión del cine. Es decir, cada uno de los mundos que se crean son representados como pequeñas escenas de diferentes películas que unidas forman una totalidad. Sin embargo, algo que ya hizo Walt Disney en su primer parque temático fue nutrirse de las narrativas transmedia. Aprovechó sus personajes y sus historias para poder construir mundos de fantasía e ilusión. Walt Disney había planteado que Disneyland era como entrar en un mundo real lleno de personajes animados y mundos fantásticos. Quería que la experiencia fuera totalmente inmersiva y que los visitantes formaran parte de ella. No quería que la gente saliera de la historia y por ello creía que todos los detalles debían concordar, hasta el punto que las farolas o las papeleras debían encajar con cada de los mudos de parque.

Un punto importante es el planteamiento del mundo Harry Potter en el parque, ya que presenta un gran cambio. No es 
necesario que los visitantes quieran ser Harry Potter, Ron o Hermione. Simplemente, quieren ser ellos mismos vestidos con las diferentes casas de Hogwarts y sentirse que forman parte del mundo de magia. Este concepto rompe con los paradigmas establecidos, ya que los visitantes han pasado de querer ser como el personaje a formar parte de la historia. Por este motivo, una de las tendencias temáticas de los parques son las aventuras interactivas. Con todo ello se consigue que los visitantes se sientan atraídos y que, a la vez, tengan una experiencia inmersiva.

Para ello, como hemos podido observar es muy importante cómo se presenta el mundo y todos sus detalles. Cuantos más detalles, más satisfacción tienen los visitantes. Sin embargo, la creación de una buena temática y un buen mundo permitirá que los visitantes disfruten de la experiencia. Y que no se cometa el error de California Adventure, ya que supuso para la empresa un gasto que iba más allá del presupuesto inicial. En el momento que un parque Disney triunfa es porque tiene logros con la imagen y la ilusión que transmite. California Adventure fracasó porque inicialmente no supo reflejar una buena imagen de California. Por lo tanto, faltaba que los huéspedes se sintieran atraídos. No fue capaz de dar una visión de futuro utópico para California, al igual que Tomorrowland y tampoco daba una imagen de madurez. Actualmente, la compañía de animación todavía está en fase de reparación de algunos de sus parques como el caso de Disney Studios de París y expandirlo para que los visitantes puedan tener más experiencias y más atracciones.

Finalmente, podemos decir que la narrativa, junto con la inmersión, provoca que el visitante se sienta atraído y quiera ir a visitar el parque. Sin embargo, los valores de la sociedad cambian como la tecnología, los valores, la movilidad, la economía, entre otros factores. Todo esto, supone un gran reto para los parques, ya que deben disponer de presupuesto para adaptarlo y atraer a nuevos visitantes y mantener los que repiten la experiencia. Sin embargo, los parques temáticos sólo están reservados para unas empresas determinadas, ya que el ritmo que marca el mundo sólo lo pueden seguir las compañías más grandes y con más presupuesto. Como hemos visto, los parques temáticos más emblemáticos son aquellos que se dedican al mundo del cine y que ofrecen la posibilidad de vivir experiencias únicas de las películas, series o personajes más populares y emblemáticos.

\section{Notas al final}

1. Hogsmeade: Es el único pueblo íntegramente mágico creado por J.K. Rowling en sus libros de Harry Potter. Está situado en los alrededores de Hogwarts y los alumnos, a partir de tercer curso, pueden visitarse ocasionalmente.

2. Hogwarts: Escuela de magia y brujería. Creada por la autora de la saga de las aventuras del joven mago, Harry Potter.

3. Toilette: Traducido del francés al castellano significa lavabo.

4. Belle Époque: Pertenece a el período entre finales de la Guerra Franco-prusiana en 1871 a principios de la Primera Guerra Mundial en 1914. En el mundo del arte fue muy importante, ya que, a principios de siglo $X X$, rompió con los cánones establecidos y sentían una gran admiración hacia la tecnología.

5. Walt Disney Imagineering: es una empresa que desarrolló Walt Disney destinada a investigar y crear nuevas experiencias en los parques.

6. Michael Einser: Fue directivo y empresario de Estados Unidos. Su carrera destaca porque fue el jefe de operaciones de Paramount Pictures en 1976 a 1984. A continuación, pasó a ser el director ejecutivo de The Walt Disney Company donde inició su carrera en 1984 hasta el 2005.

7. EPCOT: Es el segundo parque de Walt Disney World Resort en Florida. Walt lo empezó pero no pudo llevar a cabo.

8. Mickey Mouse: Es un personaje de ficción creado en 1928 por la compañía The Walt Disney. Representa un emblema y por este motivo está representado en la empresa.

9. Muggles: J.K. Rowling utiliza este término para referirse a la gente no mágica del mundo Harry Potter.

10. Storyteller: El storytelling es el arte de contar historias. Por tanto, la storyteller es quien se encarga de escribir y narrar las historias.

11. Share: Es la representación del porcentaje de la audiencia de los canales convencionales como por ejemplo la radio o la televisión.

12. IAAPA: Conocida como la International Association of Amusement Parks and Attractions.

\section{Bibliografía}

Archer, K. (Ed.) (1996). Packaging the place. Development strategies in Tampa and Olrando. Mansell.

Brill, K. M. (1993). From concept to create: theming parks. Funworld, November, 24-28

Chaspoul, C. (2001) Thématisation. Une nécessité marketing?. Espaces, tourisme et loisirs, (182), 21-43.

Chazaud, P. (1998) Le parc à theme, production touristique hors sol. Chaier Espaces, (58), 88-96.

Clave, S. A. (2005). The Global Theme Park Industry. CABI.

Formica, S. y Olsen, M.D. (1998). Trends in the amusement park industry. International Journal of Contemporary Hospitality Management, 10(7), 297-308. https://doi.org/10.1108/09596119810240933

HTR (1999). Les parcs de loisirs. L'apogée des forts en themes. Diciembre, 15-21.

IAAPA (1993). Guidelines to establish effective operations programs for amusement parks and attracctions. Alexandria

Ingram, S. (2016). Themeparks, Nostalgia, Retro. En Here You Leave Today: Time and Temporality in Theme Parks International Conference, Johannes Gutenberg University Mainz, Germany.

Iwerks, L. (2019). The Imagineering Story. [Documental]. Buena Vista, CA: Iwerks \& Co.

Lukas, S. A. (2012). The Immersive Worlds Handbook: Designing Theme Parks and Consumer Spaces. Taylor \& Francis.

McClung, G. W. (1991) Theme park selection. Factors influencing attendance. Tourism Management, 12(2) 132-140. https://doi. org/10.1016/0261-5177(91)90068-5

Milman, A. (2001) The future of the theme park and attraction industry: a management perspective. Journal of Travel Research, 40(2), 139-147. https://doi.org/10.1177\%2F004728750104000204

RAE. (s/d). Real academia Española. https://www.rae.es

Ren, H. (1998) Economies of culture: theme parks, museums and capital accumulation in China, Hong Kong and Taiwan. (Tesis 
doctoral). Washington: University of Washington.

Samuelson, D. y Yegoiants, W. (2001) The American Amusement Park. MBI Publishing Company.

Swartzman, E. (1995) Main Attractions. Leisure Management, 15(9), 65-67.

Wizarding World (2021). Harry Potter Fan Club. Wizardingworld.com. https://www.wizardingworld.com

Wong, K.K.F. y Cheung, P.W.Y. (1999) Strategic theming in theme park marketing. Journal of Vocation Marketing, 5(4), 319-332. https://doi. org/10.1177\%2F135676679900500402

Wootton, G. y Stevens, T. (1994) Staying alive. How will future trends affect theme parks?. Leisure Management, 14(12), 43-52.

Zins (1993). Enjeux stratégiques des parcs thématiques: Amérique du Nord et Europe. Téoros. 12(3), 5-9.

\section{CV}

Elisabet Fonts. Licenciada en Comunicación Audiovisual. Docente y coordinadora en el Centre de la Imatge i la Tecnologia Multimèdia (CITM) a la Universitat Politècnica de Catalunya. Ha colaborado en la Universidad de Barcelona y en la Universitad de Vic. Las asignaturas que imparte en diferentes grados están focalizadas en el ámbito de la animación 3D, 2D y el arte digital en diferentes ámbitos.

Jaume Duran. Doctor en Comunicación Audiovisual, es licenciado en Filología, en Lingüística y en Historia del Arte. Colabora o ha colaborado con la Universitat de Barcelona, la ENTI, ESCAC, La Salle - Universitat Ramon Llull, la Universitat Autònoma de Barcelona y la Universitat Oberta de Catalunya, entre otros. Es profesor, ensayista y realizador.

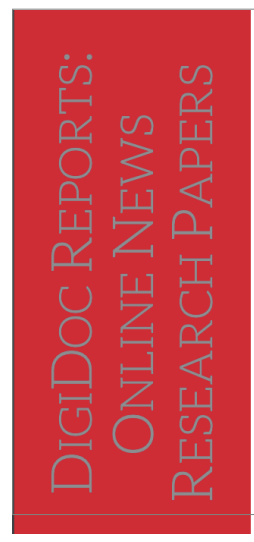

\section{Researching the news \\ in the hybrid media system: \\ An expert panel report}

\begin{tabular}{r|l} 
upf. & $\begin{array}{l}\text { Universitat } \\
\text { Pompeu Fabra } \\
\text { Barcelona }\end{array}$ \\
\cline { 1 - 2 }
\end{tabular}

Irene Costera Meijer, Richard Rogers,

Oscar Westlund \& Tamara Witschge

DigiDoc

Javier Díaz-Noci \& Ana Serrano (eds.)

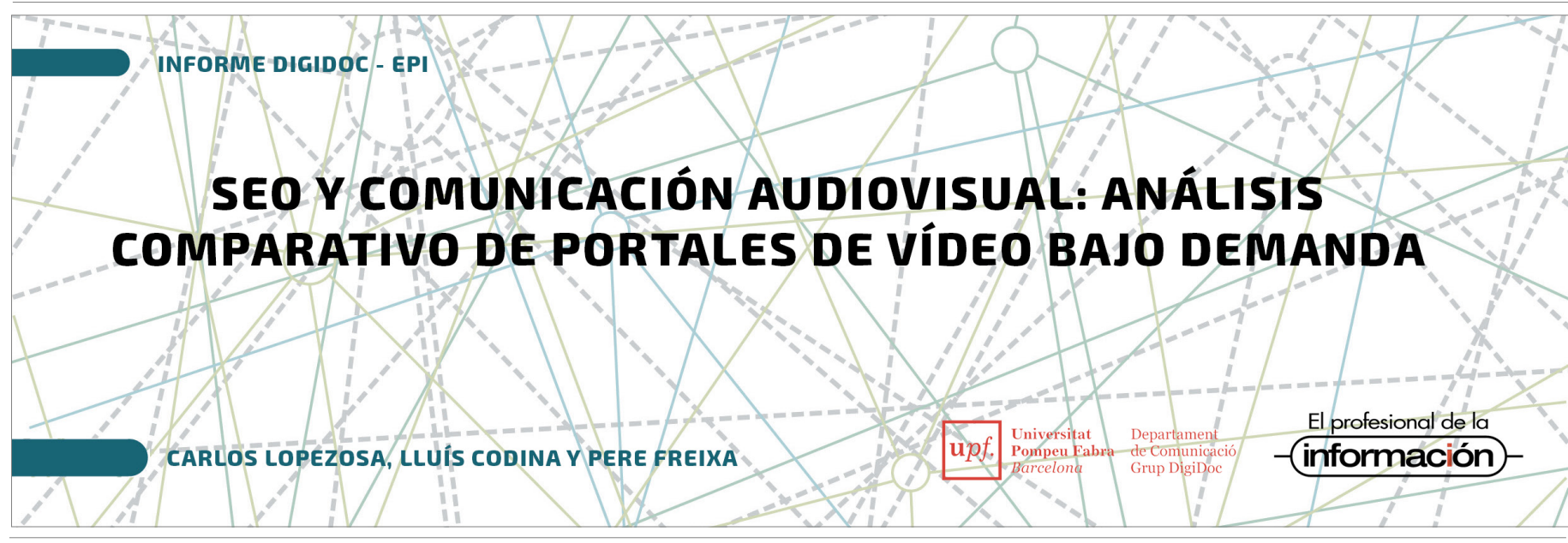

\section{.}

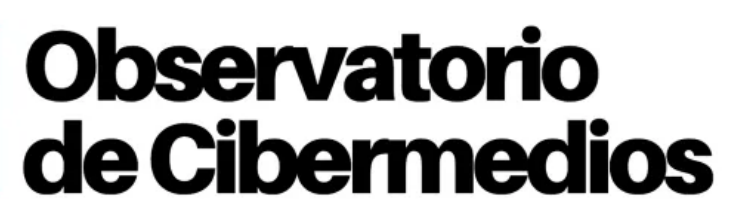

El Observatorio de Cibermedios es una producción del Grupo de Investigación en Documentación Digital y Comunicación Interactiva (DigiDoc) del Departamento de Comunicación de la Universitat Pompeu Fabra.

\section{https://observatoriocibermedios.upf.edu/}

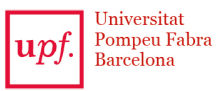

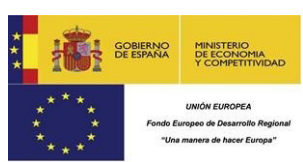

El Observatorio de Cibermedios (OCM) forma parte del proyecto del Plan Nacional "Narración interactiva y visibilidad digital en el documental interactivo y el periodismo estructurado". RTI2018-095714-B-C21 (MINECO/FEDER), Ministerio de Ciencia, Innovación y Universidades (España). 